\title{
Sleep problems in anxious and depressive older adults
}

This article was published in the following Dove Press journal:

Psychology Research and Behavior Management

II June 2015

Number of times this article has been viewed

\author{
Marie-France Leblanc' \\ Sophie Desjardins' \\ Alain Desgagné ${ }^{2}$ \\ 'Department of Psychology, \\ Université du Québec à Trois- \\ Rivières, Trois-Rivières, ${ }^{2}$ Department \\ of Mathematics, Université du \\ Québec à Montréal, Montréal, QC, \\ Canada
}

Correspondence: Sophie Desjardins Département de psychologie, Université du Québec à Trois-Rivières, CP 500,

Trois-Rivières, QC G9A 5H7, Canada

$\mathrm{Tel}+$ I 819376501 I

Fax +I 8193765195

Email sophie.desjardins@uqtr.ca
Purpose: The objective of this study was to identify the sleep problems most often encountered by the elderly according to the presence or absence of anxiety and mood disorders. The aim was also to determine whether groups of anxious, depressive, and asymptomatic individuals differ in relation to sleep onset latency; awakenings at night or early in the morning; subjective quality of sleep; taking of sleep medication; and daytime sleepiness.

Methods: Structured interviews based on the DSM-IV-TR were administered to a sample of 2,759 seniors aged 65 years and older at the participants' home by health professionals.

Results: Awakening was found to be the most common disturbance. Increased sleep onset latency was the second most frequent sleep difficulty. Taking more than 30 minutes to fall asleep was associated with the likelihood of meeting the diagnostic criteria for an anxiety disorder, and even reduced the risk of meeting the diagnostic criteria for a mood disorder rather than an anxiety disorder. Awakenings were associated with the probability of suffering from an anxiety disorder or a mood disorder. Quality of sleep, as perceived by the elderly, was not found to be associated with the probability of suffering from a mental disorder.

Conclusion: These findings should help to facilitate the practitioner's diagnosis and add further nuances to be considered when encountering symptoms of an anxious or depressive appearance. All of these data also add fuel to the ongoing debate about whether anxiety and depression are one or two distinct categories of disorders.

Keywords: anxiety, awakenings, daytime sleepiness, depression, elderly, quality of sleep, sleep medication, sleep onset latency

\section{Introduction}

Approximately 50\% of US seniors report sleep difficulties, ${ }^{1}$ with similar percentages found in Canada, ${ }^{2}$ and slightly lower proportions in Brazil. ${ }^{3,4}$ In France, up to $70 \%$ of older individuals report sleep problems, ${ }^{5}$ as do $44.2 \%$ of seniors in Italy. ${ }^{6}$

Various types of psychiatric problems have been associated with sleep disturbances in the elderly. ${ }^{7-10}$ A more specific link to depression has sometimes been noted..$^{1,5,8,11,12}$ Depression is considered a risk factor for sleep difficulties. ${ }^{1,5}$ It has been linked to low sleep efficiency and poor quality of sleep, ${ }^{13-15}$ more frequent awakening, , $^{34,16-18}$ increased sleep onset latency, ${ }^{5,15,19}$ and daytime sleepiness. ${ }^{6,8,18,20,21}$ These sleep problems in turn increase the risk of depression. ${ }^{11,18}$ More specifically, such an association has been found between depression and poor sleep quality, ${ }^{14}$ problems falling asleep, ${ }^{16,17}$ premature early-morning awakening, ${ }^{14,18}$ daytime sleepiness, ${ }^{18}$ and the use of psychotropic drugs to combat insomnia. ${ }^{14}$

Anxiety is in turn linked to a greater likelihood of poor sleep efficiency and awakening at night, ${ }^{22}$ increased sleep onset latency, ${ }^{19,23}$ poor quality of sleep, ${ }^{20}$ and 
daytime sleepiness. ${ }^{21}$ Finally, overall, less anxiety and depression are observed in good sleepers than in poor sleepers. $^{24}$

In Québec, Canada, a lifetime prevalence of $11.8 \%$ (or $3.3 \%$ within the past 12 months) for at least one anxiety or mood disorder is found among the elderly. ${ }^{25}$ In the United States, $15.2 \%$ of individuals over age 55 years had presented a clinically significant mental disorder within the past year, with $11.4 \%$ having had an anxiety disorder, and 3.4\%-7.2\% having experienced a mood disorder. ${ }^{26}$

Although a significant comorbidity seems to exist between sleep problems and depression, on the one hand, and between sleep problems and anxiety, on the other, the underlying mechanisms are not well understood..$^{27,28}$

No large-sample study has to date systematically and simultaneously examined all of the sleep problems discussed above and anxiety and mood disorders in the elderly. For example, the study by van den Berg et al ${ }^{21}$ links anxiety and mood disorders diagnosed using DSM-IV-TR criteria, sleep onset latency, and the overall score for sleep difficulties. These two variables were found to be associated with the two types of mental disorders. The study by Mallon et $\mathrm{al}^{19}$ explored sleep onset latency and awakening, separated into nocturnal and early-morning awakening, along with the taking of sleep medication. However, the presence of mental disorders was verified by using the Hospital Anxiety and Depression Scale, ${ }^{29}$ the 14 questions of which are useful in detecting depression and anxiety but do not verify all of the DSM-IV-TR required criteria. The researchers thus found a link between increased sleep onset latency and the two categories of disorders, whereas the two types of awakening were more specifically associated with depression. It would therefore seem appropriate to verify the links between each of the sleep problems and mental disorders meeting the DSM-IV-TR criteria in a large sample of the elderly. The results found will enable us to add to the studies that allow us to better understand the mechanisms linking sleep problems to anxiety and mood disorders, and thereby help to improve the effectiveness of treatments for these disorders.

The objective of this study is to identify the sleep problems most often encountered by the elderly according to the presence or absence of anxiety and mood disorders. The aim is also to determine whether groups of anxious, depressive and asymptomatic individuals differ in relation to the variables of interest: ie, the various sleep problems.

\section{Methods}

\section{Participants}

The study protocol was reviewed and approved by the ethics committee of the Institut Universitaire de Gériatrie de Sherbrooke. Data for this cross-sectional study were obtained from the longitudinal Québec Survey on Seniors' Health (Enquête sur la santé des aînés) conducted during 2005-2008. ${ }^{30}$ The aim of the survey was to assess the physical and mental health of the French-speaking community-dwelling population aged over 65 years in the province of Québec, Canada. This study was based on a sample of 2,759 participants aged 65 years and older. The participants' average age was 73.8 years, and they were selected according to a method of random generation of telephone numbers and a sampling strategy based on their geographic location in Québec's 16 administrative regions. Ninety-minute-long structured interviews were administered at the participants' homes by health professionals who had been given 2 days of training on the computerized questionnaire, which was based on the DSM-IV-TR and was similar to other questionnaires of this type, such as the Diagnostic Interview Schedule, which has a good degree of validity and reliability. ${ }^{31}$ The questionnaire was adapted for older persons. ${ }^{32,33}$ The interview also included basic questions on sociodemographic data. The questions related to sleep were inspired by the Pittsburgh Sleep Quality Index ${ }^{34}$ translated into French. The health professionals explained the goal of the study to the participants and had them sign a consent form. Participants received a financial compensation of $\$ 30$. Administration of the Mini-Mental State Examination ${ }^{35}$ was used to exclude participants with a score of less than 22. Just over half of the participants were women, and $58.1 \%$ were under 75 years of age. Nearly half of the participants reported having a spouse, and almost $65 \%$ had a secondary or lower level of schooling. The participants were virtually equally divided in terms of household income, of either over or under $\$ 25,000$. Finally, almost one-third of the participants had a sleep efficiency (ie, the ratio of the time spent sleeping to the time spent in bed multiplied by 100 ) of less than $80 \%$.

\section{Variables}

The variables under study are sleep problems and anxiety and mood disorders. The variables related to sleep are the following: difficulty falling asleep; nocturnal or early-morning awakening; overall sleep quality; daytime sleepiness; and the taking of sleep medication. The participants answered the following questions: "In the past month, how many times did you find it hard to sleep because you were unable to fall 
asleep within 30 minutes?"; "In the past month, how many times did you find it hard to sleep because you woke up in the middle of the night or early in the morning?"; "In the past month, how would you evaluate your overall sleep quality?"; "In the past month, how many times did you take medication (whether prescribed or not) to help you sleep?"; and "In the past month, how many times did you find it hard to stay awake while driving, eating or engaging in a social activity?". The possible answers were: not in the past month; less than once a week; once or twice a week; and three or more times a week. In order to properly conduct the statistical analyses, these answers were divided into two categories: ie, less than once a week and at least once a week. The covariables under study are age (over or under 75 years), sex, annual household income (above or below $\$ 25,000$ ), marital situation (living as a couple or alone), schooling (none to secondary or postsecondary), and sleep efficiency estimated at over $80 \%$ (calculated based on a series of elements: time taken to fall asleep, bedtime, number and duration of awakenings, etc). The time spent sleeping was then divided by the time spent in bed, and the quotient thus obtained was multiplied by 100 .

To form the groups, the DSM-IV-TR diagnostic criteria were used based on the structured interviews with all the participants. Three groups were thus formed based on the diagnostic criteria for mood or anxiety disorders. The group affected by mood disorders ( $n=161)$ was made up of participants meeting the diagnostic criteria for a major depression, a minor depression, or a mania. The group with anxiety disorders $(n=103)$ was composed of participants meeting the criteria for an obsessive-compulsive disorder, a generalized anxiety disorder, a panic disorder, or a specific or social phobia. The group of asymptomatic individuals $(n=2,495)$ included all participants not exhibiting a mood or anxiety disorder. The too few participants presenting both an anxiety and a mood disorder $(\mathrm{n}=28)$ were excluded.

\section{Statistical analysis}

In including all of the variables and covariables under study, $\chi^{2}$ tests were conducted using PASW Statistics 18.0 where the threshold of significance was set at $P<0.05$. The idea was to obtain an overall profile of the three groups under study and to identify the differences between them. A multinomial logistic regression analysis was then performed, and a fully adjusted model was used to evaluate the distinct risk of suffering from an anxiety or mood disorder according to the presence or absence of a sleep problem, since the statistical analysis takes into account the contribution of all the variables investigated and verifies the specificities of each.

\section{Results}

Table 1 presents the descriptive statistics according to the presence or absence of a mental disorder, and, more specifically, an anxiety or mood disorder. The problem most frequently reported by all of the older persons was nocturnal or early-morning awakening, at least once a week. In the asymptomatic seniors, fewer than a third reported taking more than 30 minutes to fall asleep, experiencing nocturnal or early-morning awakening, or taking a sleep medication. More than $90 \%$ of the asymptomatic group also considered their sleep to be of good quality, whereas more than one in four of the depressive or anxious seniors evaluated their sleep quality as being quite poor or very poor. In addition, more than half of the depressive older individuals took more than 30 minutes to fall asleep or woke up at night or early in the morning at least once a week. More depressive and anxious seniors than asymptomatic older individuals used a sleep medication.

Of the five sleep difficulties evaluated, daytime sleepiness was the problem least often reported by the three groups of participants; indeed, fewer than $4 \%$ of the asymptomatic elderly found it hard to stay awake at least once a week as they drove, ate, or engaged in a social activity. This level was twice as high for the anxious and depressive seniors.

Compared with asymptomatic older persons, a greater number of depressive or anxious seniors took more than 30 minutes to fall asleep, experienced nocturnal or earlymorning awakening, suffered poor sleep quality, used sleep medication, or felt daytime sleepiness. More depressive elders than anxious or asymptomatic older persons experienced increased sleep onset latency or daytime sleepiness or took sleep medication.

Women and younger seniors (under 75 years of age) were found to be overrepresented in the groups of depressive and anxious elderly, which was also the case with sleep efficiency, which was more often less than $80 \%$ in depressive and anxious seniors than in asymptomatic older persons.

Before continuing, we should mention that the percentage of classification accuracy was $90.7 \%$, and that the multicollinearity was verified, with no problems found in that respect, as the statistical tolerance levels were higher than 0.20 . Table 2 shows the results of the regression analysis. These data indicate that waking frequently at night or too early in the morning, taking sleep medication, and often feeling sleepy 
Table I Descriptive statistics for the sociodemographic variables according to the presence or absence of an anxiety or mood disorder

\begin{tabular}{|c|c|c|c|c|c|c|c|}
\hline & \multicolumn{2}{|c|}{ Asymptomatic } & \multicolumn{2}{|c|}{ Depressive } & \multicolumn{2}{|c|}{ Anxious } & \multirow[t]{2}{*}{$\chi^{2}$} \\
\hline & $\mathbf{n}$ & $\%$ & $\mathbf{n}$ & $\%$ & $\mathbf{n}$ & $\%$ & \\
\hline More than 30 minutes to fall asleep & & & & & & & $* *$ \\
\hline Less than once a week & $\mathrm{I}, 788$ & 71.9 & 104 & 44.1 & 45 & 64.6 & \\
\hline At least once a week & 700 & 28.1 & 57 & 55.9 & 57 & 35.4 & \\
\hline Awakening at night or early in the morning & & & & & & & $* *$ \\
\hline Less than once a week & $\mathrm{I}, 68 \mathrm{I}$ & 67.4 & 69 & 42.9 & 44 & 43.6 & \\
\hline At least once a week & 813 & 32.6 & 92 & 57.1 & 57 & 56.4 & \\
\hline Subjective quality of sleep & & & & & & & ** \\
\hline Quite good or very good & 2,277 & 91.3 & 128 & 79.5 & 78 & 75.7 & \\
\hline Quite poor or very poor & 217 & 8.7 & 33 & 20.5 & 25 & 24.3 & \\
\hline Taking of sleep medication & & & & & & & ** \\
\hline Less than once a week & 1,949 & 78.3 & 93 & 57.8 & 68 & 66.7 & \\
\hline At least once a week & 541 & 21.7 & 68 & 42.2 & 34 & 33.3 & \\
\hline Daytime sleepiness & & & & & & & $* *$ \\
\hline Less than once a week & 2,407 & 96.7 & 147 & 91.3 & 96 & 93.2 & \\
\hline At least once a week & 82 & 3.3 & 14 & 8.7 & 7 & 6.8 & \\
\hline Age & & & & & & & $*$ \\
\hline Under 75 years & $\mathrm{I}, 430$ & 57.3 & 107 & 66.5 & 65 & 63.7 & \\
\hline 75 years and over & $\mathrm{I}, 064$ & 42.7 & 54 & 33.5 & 37 & 36.3 & \\
\hline Sex & & & & & & & $* *$ \\
\hline Male & $\mathrm{I}, 057$ & 42.4 & 46 & 28.6 & 29 & 28.4 & \\
\hline Female & $\mathrm{I}, 438$ & 57.6 & 115 & 71.4 & 73 & 71.6 & \\
\hline \multicolumn{8}{|l|}{ Civil status } \\
\hline Married or living together & 1,150 & 46.3 & 70 & 44.0 & 50 & 49.5 & \\
\hline Single, separated, divorced, or widowed & 1336 & 53.7 & 83 & 56.0 & 51 & 50.5 & \\
\hline \multicolumn{8}{|l|}{ Schooling } \\
\hline None to secondary & 1,618 & 64.9 & 108 & 67.1 & 58 & 56.3 & \\
\hline Postsecondary & 876 & 35.1 & 53 & 32.9 & 45 & 43.7 & \\
\hline \multicolumn{8}{|l|}{ Annual household income } \\
\hline Under $\$ 25,000$ & 1,229 & 49.3 & 77 & 47.5 & 51 & 49.5 & \\
\hline$\$ 25,000$ and over & 1,264 & 50.7 & 85 & 52.5 & 52 & 50.5 & \\
\hline Sleep efficiency & & & & & & & $*$ \\
\hline $80 \%$ or more & 1,624 & 72.5 & 94 & 65.3 & 56 & 61.5 & \\
\hline Less than $80 \%$ & 617 & 27.5 & 50 & 34.7 & 35 & 38.5 & \\
\hline
\end{tabular}

Notes: $* p<0.05 ; * * P<0.01$.

during the day are problems associated with the distinct risk of meeting the diagnostic criteria for a mood disorder (rather than being asymptomatic). The facts of awakening often and experiencing increased sleep onset latency are problems associated with the risk of meeting the diagnostic criteria for an anxiety disorder (rather than being asymptomatic). It should be noted that quality of sleep, as perceived by the elderly, was not found to be associated with the probability of suffering from a mental disorder.

\section{Discussion}

The primary objective of this study was to establish which sleep problems affected the elderly the most based on the presence or absence of an anxiety or mood disorder. Our results have highlighted significant differences between seniors suffering from a mood disorder or an anxiety disorder and those who are asymptomatic in regard to all of the sleep difficulties. In fact, the mean for all of the problems taken together gives a level of $18.9 \%$ of asymptomatic elderly participants showing sleep difficulties compared with an overall mean of $34.1 \%$ of seniors suffering from a mental disorder and at least one sleep problem. These levels are more conservative than those reported in the literature. The asymptomatic older persons also have sleep problems, but the levels observed for this group without a mental disorder run counter to those indicated in the literature on detrimental developmental changes said to affect all of this population. $4,8,9,36,37$

When we look at each of the sleep problems, we see that awakening was the most common disturbance. Next, increased sleep onset latency was the second most frequent sleep difficulty. These two problems have been traditionally associated with mood or anxiety disorders. ${ }^{38}$ Nearly a quarter of the participants took sleep medication at least once 
Table 2 ORs and Cls for sleep problems predicting the presence or absence of an anxiety or mood disorder

\begin{tabular}{|c|c|c|c|c|c|c|}
\hline & \multicolumn{2}{|c|}{$\begin{array}{l}\text { Depressive vs } \\
\text { asymptomatic }\end{array}$} & \multicolumn{2}{|c|}{$\begin{array}{l}\text { Anxious vs } \\
\text { asymptomatic }^{\mathrm{a}}\end{array}$} & \multicolumn{2}{|c|}{$\begin{array}{l}\text { Depressive vs } \\
\text { anxious }^{\mathrm{a}}\end{array}$} \\
\hline & OR & $95 \% \mathrm{Cl}$ & OR & $95 \% \mathrm{Cl}$ & OR & $95 \% \mathrm{Cl}$ \\
\hline \multicolumn{7}{|l|}{ More than 30 minutes to fall asleep } \\
\hline Less than once a week & 1.38 & $0.90-2.11$ & $0.46 * *$ & $0.28-0.76$ & $3.01 * *$ & $1.59-5.69$ \\
\hline At least once a week & 1.00 & & 1.00 & & 1.00 & \\
\hline \multicolumn{7}{|l|}{ Awakening at night or early in the morning } \\
\hline Less than once a week & $0.40 * *$ & $0.27-0.59$ & $0.59 *$ & $0.36-0.97$ & 0.67 & $0.36-1.25$ \\
\hline At least once a week & 1.00 & & 1.00 & & 1.00 & \\
\hline \multicolumn{7}{|l|}{ Subjective quality of sleep } \\
\hline Quite good or very good & 0.65 & $0.39-1.10$ & 0.61 & $0.33-1.13$ & 1.07 & $0.50-2.30$ \\
\hline Quite poor or very poor & 1.00 & & 1.00 & & 1.00 & \\
\hline \multicolumn{7}{|l|}{ Taking of sleep medication } \\
\hline Less than once a week & $0.38 * *$ & $0.26-0.56$ & 0.69 & $0.42-1.13$ & 0.55 & $0.31-1.01$ \\
\hline At least once a week & 1.00 & & 1.00 & & 1.00 & \\
\hline \multicolumn{7}{|l|}{ Daytime sleepiness } \\
\hline Less than once a week & $0.35^{* *}$ & $0.19-0.66$ & 0.60 & $0.26-1.39$ & 0.59 & $0.22-1.58$ \\
\hline At least once a week & 1.00 & & 1.00 & & 1.00 & \\
\hline \multicolumn{7}{|l|}{ Age } \\
\hline Under 75 years & $1.76 * *$ & $1.20-2.58$ & 1.25 & $0.79-1.98$ & $1.4 \mathrm{I}$ & $0.79-2.52$ \\
\hline 75 years and over & 1.00 & & 1.00 & & 1.00 & \\
\hline \multicolumn{7}{|l|}{ Sex } \\
\hline Male & $0.5 I^{* *}$ & $0.34-0.77$ & $0.60 *$ & $0.37-0.99$ & 0.85 & $0.45-1.59$ \\
\hline Female & 1.00 & & 1.00 & & 1.00 & \\
\hline \multicolumn{7}{|l|}{ Civil status } \\
\hline Married or living together & 0.85 & $0.58-1.25$ & 1.48 & $0.92-2.36$ & 0.57 & $0.32-1.03$ \\
\hline Single, separated, divorced or widowed & 1.00 & & 1.00 & & 1.00 & \\
\hline \multicolumn{7}{|l|}{ Schooling } \\
\hline None to secondary & 1.21 & $0.8 \mathrm{I}-\mathrm{I} .82$ & $0.60 *$ & $0.38-0.95$ & $2.04 *$ & $1.13-3.68$ \\
\hline Postsecondary & 1.00 & & 1.00 & & 1.00 & \\
\hline \multicolumn{7}{|l|}{ Annual household income } \\
\hline Under $\$ 25,000$ & 0.73 & $0.49-1.08$ & 0.95 & $0.58-1.54$ & 0.77 & $0.42-|.4|$ \\
\hline$\$ 25,000$ and over & 1.00 & & 1.00 & & 1.00 & \\
\hline \multicolumn{7}{|l|}{ Sleep efficiency } \\
\hline $80 \%$ or more & 0.84 & $0.84-2.03$ & 1.29 & $0.76-2.19$ & 1.02 & $0.52-1.97$ \\
\hline Less than $80 \%$ & 1.00 & & 1.00 & & 1.00 & \\
\hline
\end{tabular}

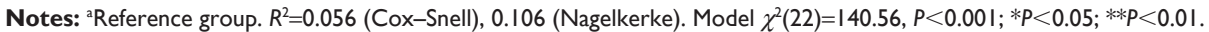

Abbreviations: $\mathrm{Cl}$, confidence interval; OR, odds ratio.

a week, which several researchers have shown to be a solution widely used by the elderly. ${ }^{37,39,40}$ The latter proportion may also explain the relatively low levels of sleep problems found among the seniors. The least frequent sleep difficulties were the poor perceived quality of sleep and daytime sleepiness. The older persons in this sample reported little daytime sleepiness despite the fact of this being a common developmental change in this population, according to the reports in the literature, ${ }^{41,42}$ the way of measuring daytime sleepiness was perhaps not the most appropriate. Elderly persons suffering from a mental disorder report more daytime sleepiness and poor quality of sleep.

The second objective was to examine the relations between sleep problems and mental disorders. The main finding in this study was that the sleep problems more present in the seniors suffering from a mental disorder do not all have a significant relationship with a mental disorder.

It was found that older persons affected by two or three types of the sleep problems studied had a greater likelihood of suffering from one of the two types of mental disorders under study. Indeed, seniors who awaken often during the night or early in the morning, who use sleep medication, or who are sleepy during the day were more at risk of being depressive. Older individuals who take more time to fall asleep and who wake up often during the night or early in the morning ran a greater risk of being anxious.

Taking more than 30 minutes to fall asleep was in fact associated with the likelihood of meeting the diagnostic criteria for an anxiety disorder, and even reduced the risk of meeting the diagnostic criteria for a mood disorder rather than 
an anxiety disorder. The link between increased sleep onset latency and anxiety may be explained by the neurovegetative activation observed in anxiety disorders, ${ }^{38,43}$ which may be associated with this manifestation at bedtime, a period conducive to rumination. ${ }^{7}$ The thoughts present at bedtime are in this case said to be along the lines of lack of control, apprehension, intolerance to uncertainty, and excessive worries about the future ${ }^{38,43-45}$ Anxious elderly persons are able to maintain a high level of motivation, but their thoughts at bedtime, if directed toward solving a problem, prove to be ineffectual $1^{43,44}$ and encourage a longer sleep onset latency. Given this information, the lack of a significant association between mood disorders and the fact of taking more time to fall asleep is understandable. Depressive persons are often subject to hypersomnia and fatigue, and are likely to fall asleep more quickly than anxious individuals. Their slowed neurovegetative functioning, fatigue, and loss of interest are more favorable to sleep than the situation of alertness prevailing in anxious persons. The lassitude characteristic of many of the depressed is less detrimental to the capacity to fall asleep than the hypervigilance of the anxious.

Awakenings are associated with the probability of suffering from an anxiety disorder or a mood disorder. In this regard, it is worth reiterating that one of the neurotransmitters involved in maintaining sleep is among those active during the processes of both depression and anxiety: ie, serotonin..$^{38,46}$ In terms of the link between awakening and anxiety, we understand that hyperactivity, hypervigilance, worries, and a state of alertness are conditions that are conducive to nocturnal awakenings. Awakenings are also associated with mood disorders. One may presume that the loss of interest, turning inward, and fatigue that are often encountered with depression tend to foster a lower level of physical activity during the day, with the resultant negative consequences in terms of sleeping at night. We can also hypothesize that awakenings are more passive in people suffering from depression who have slept a great deal and may perhaps be less sleepy, compared with the more active awakenings of people suffering from anxiety, who start to worry as soon as they open their eyes. The levels of this sleep problem are twice as low for the asymptomatic older participants. In this case, it is more appropriate to investigate other reasons for such awakenings, such as nocturia, ${ }^{47}$ cessation of nicotine consumption, ${ }^{48}$ use of a nicotine replacement therapy, ${ }^{49}$ chronic pain, ${ }^{50}$ obstructive pulmonary diseases, high blood pressure and pain, ${ }^{51}$ and the consumption of caffeine ${ }^{38,52,53}$ or alcohol..$^{38,54}$

We find that the seniors suffering from a mood disorder are those who most tend to use medication to reduce their symptoms, including their sleep problems. We also know that the taking of sleep medication is associated with the risk of suffering from a mood disorder (rather than being asymptomatic). Explicit requests for sleep medication may thus be an indicator of the presence of a mood disorder, as depressed individuals tend to focus on negative elements and this may motivate their need to benefit from the use of sleep medication..$^{38}$ Indeed, the fear of sleeping badly and thus seeing their fatigue increase seems to make them feel that pharmacological solutions are acceptable. Their ruminations about the causes and consequences of possible or existing sleep problems discourage a more proactive means of solving their problems than medication. ${ }^{45,55}$

Daytime sleepiness is more often present in older people suffering from mental disorders and is the least common sleep difficulty. It is linked to the risk of being affected by a mood disorder, and this link has been highlighted in studies focusing on the benefits of exercise, in terms of daytime sleepiness, for depressed individuals. ${ }^{7,56,57}$ Daytime sleepiness that affects asymptomatic persons may be due to sleep apnea, which occurs more often with advanced age and affects sleep. ${ }^{58}$ In case of doubt, a differential diagnostic approach is clearly called for. Lowering of mood is associated with this daytime manifestation, and it is indeed of interest to practitioners whose patients are complaining about this symptom to consider it as a potential indicator of depression, once it has been differentiated from sleep apnea. It has been found that daytime sleepiness is not associated with the probability of being affected by an anxiety disorder. When we are aware of the mechanisms involved in anxiety disorders - ie, physiological activation which causes an accelerated heart rate; increased blood pressure and alertness; cortisol production; enhanced perceptual awareness; rapid cognitive processing; and faster motor responses ${ }^{38,43,59}$ - it is not surprising to find a lack of sleepiness in this state of general alertness in anxious elderly people.

\section{Conclusion}

All of these data add fuel to the ongoing debate about whether anxiety and depression are one or two distinct categories of disorders, ${ }^{45,60,61}$ not to ignore their comorbidity, which is also frequently mentioned. ${ }^{38,62,63}$ In light of the results obtained, which offer valid estimates in terms of the risks of suffering from the mental disorders under study, we have observed a link between finding it hard to fall asleep and the risk of being anxious rather than depressive or asymptomatic. This piece of data allows us to make an interesting clarification in regard to detection of the two types of mental disorders 
and their differential diagnosis. The DSM-IV-TR in fact mentions difficulty in falling asleep as a criterion that is present in both categories of mental disorders. Our results thus provide a clarification in terms of the link between sleep onset latency and anxiety disorders. The regression analyses also enable us to observe that awakenings are associated with the probability of suffering from both an anxious and a depressed state. Verification of the nature of the thoughts present during such awakenings could offer some interesting avenues for differential diagnosis. Anxiety disorders foster cognitive hypervigilance, and worries about the future may occupy people's thoughts during these awakenings. ${ }^{38,43}$ Mood disorders in turn foster psychic asthenia and discouragement about the past, a passive anhedonia possibly accompanied by visualization congruent with negative affects. ${ }^{38,55}$ We in fact already knew that mood disorders were associated with nocturnal and early-morning awakening and that anxiety disorders were associated with interrupted sleep, but without any further distinctions. Unfortunately, one of the limitations of this study is that it did not distinguish between the types of awakenings in the formulation of the questions on sleep problems. Such a distinction might have allowed us to offer an interesting additional finding about the types of awakenings involved in the two different types of mental disorders. The available data therefore currently only enable us to support the finding about the link between awakenings and the two types of mental disorders. These same results show that the taking of medication is particular to mood disorders, as is daytime sleepiness. So the confirmed link between mood disorders and daytime sleepiness allows us to offer a further clarification in addition to the symptom of daytime hypersomnia that is sometimes reported. Daytime sleepiness, whether or not it is accompanied by periods of daytime sleep, is thus one further indicator in the detection of mood disorders. This also gives us some important information about the differential diagnosis of anxiety vs mood disorders, if we also consider the fact of the few asymptomatic seniors who report this latter problem. So, in light of the preceding data, and without being able to officially conclude about whether it is a case of one type of disorder or two separate types, these new elements help to facilitate the practitioner's diagnosis and add further nuances to be considered when encountering symptoms of an anxious or depressive appearance.

Some recommendations appear to be relevant here. First, the bringing to light of the link between sleep problems and anxiety and mood disorders reminds us of the importance of treating these disorders as soon as they are detected and of not simply targeting the reduction of sleep problems. ${ }^{1}$ Also, the presence of sleep difficulties combined with mental disorders may make it easier for people to ask for help; the elderly are clearly less afraid of revealing the poor nights that they experience than of talking about their mental disorders. ${ }^{64}$ The request for help is all the more crucial when we consider the finding of the link between sleep problems, depression, and the wish to die. ${ }^{64}$

The more specific association between people's difficulty in falling asleep and anxiety disorders shows the importance of certain recommendations. Individuals affected by an anxiety disorder are in fact better off waiting until they are sleepy before they go to bed and working on lessening thoughts and worries at bedtime. At bedtime, breathing exercises, such as maintaining a sustained focus on the sensations created by the air passing through one's nostrils, allow one to diminish the mental energy available for thought processes. Also, to make bedtime more conducive to calm and sleep and less conducive to worries, the habit of choosing a set, specific moment for solving problems during the day may allow anxious individuals to worry less when they go to bed or when they wake up during the night, and so possibly have a positive effect on their capacity to fall asleep quickly or to go back to sleep more easily when they awaken at night or too early in the morning. In addition, daytime sleepiness reported by people affected by a mood disorder may be diminished by a program of stimulating physical activities, which has also been shown to be somewhat effective in combatting mood disorders. ${ }^{65}$ Physical exercises have an effect on sleep quality as well, and consequently on the taking of sleep medication, which is something that people affected by depression in this sample also dealt with. ${ }^{66}$

A number of studies have explored the various sleep problems or mental disorders by using smaller clinical samples than is the case with the present study, which comprises 2,759 participants. Our study characteristics are comparable to those of the general elderly population in Québec, the age groups of the seniors are well distributed, and the proportions of men and women are respectable. Structured interviews have allowed us to gather the data used, thus favoring the validity of the information amassed, while keeping in mind that a crosssectional study does not enable one to assign causality to the variables and that this study is no exception. Also, we know that the use of antidepressant and anxiolytic drugs is widespread and that they are also prescribed for sleep problems. This dual usage may lead to underestimates of the number of sleep or psychiatric problems and of the interactions between them. We chose not to examine the use of psychotropic drugs, and such a choice is a frequent one according to the metaanalysis by Floyd et $\mathrm{al}^{67}$ in which the inclusion of depressive or anxious participants that could mask the detrimental effect 
of developmental changes on sleep is also noted. Also, some studies establish sleep quality based on the overall score obtained for all of the sleep difficulties, whereas the present study examines this problem by using a more direct question. It might be interesting, in a future study, to compare the two scores. The lack of an objective sleep evaluation measure such as polysomnography represents one of the limitations of our study. So it would also be relevant to add such a tool. Finally, let us note that precise data in regard to the time of nocturnal or early-morning awakenings in the form of a dichotomized variable would have added some interesting nuances in terms of determining the differences or similarities between the two types of mental disorders.

\section{Acknowledgments}

This research was supported by the Fonds de recherche en santé du Québec. The authors would like to thank the research group from the Québec Survey on Seniors' Health (Enquête sur la santé des aînés) study and Michel Préville for the acquisition of funding and the collection of data.

\section{Disclosure}

The authors report no conflicts of interest in this work.

\section{References}

1. Fok M, Stewart R, Besset A, Ritchie K, Prince M. Incidence and persistence of sleep complaints in a community older population. Int $J$ Geriatr Psychiatry. 2010;25(1):37-45.

2. MacLeod MAK. Attitudes and Beliefs about Insomnia Treatment among Older Adults with Chronic Insomnia [dissertation]. Calgary: University of Calgary; 2000.

3. Almeida OP, Tamai S, Garrido R. Sleep complaints among the elderly: results from a survey in a psychogeriatric outpatient clinic in Brazil. Int Psychogeriatr. 1999;11(1):47-56.

4. Blay SL, Andreoli SB, Gastal FL. Prevalence of self-reported sleep disturbance among older adults and the association of disturbed sleep with service demand and medical conditions. Int Psychogeriatr. 2008;20(3): $582-595$.

5. Jaussent I, Dauvilliers Y, Ancelin ML, et al. Insomnia symptoms in older adults: associated factors and gender differences. Am J Geriatr Psychiatry. 2011;19(1):88-97.

6. Bonanni E, Tognoni G, Maestri M, et al. Sleep disturbances in elderly subjects: an epidemiological survey in an Italian district. Acta Neurol Scand. 2010;122(6):389-397.

7. Beaulieu P. Traitement cognitivo-comportemental de l'insomnie chronique [Cognitive-behavioral treatment of chronic insomnia][dissertation]. Créteil: Université Val-de-Marne; 2006. Available from: http://doxa.u-pec.fr/ theses/th0243099.pdf. French. Accessed January 9, 2015.

8. Foley D, Ancoli-Israel S, Britz P, Walsh J. Sleep disturbances and chronic disease in older adults: results of the 2003 National Sleep Foundation. J Psychosom Res. 2004;56(5):497-502.

9. Ohayon MM, Zulley J, Guilleminault C, Smirne S, Priest RG. How age and daytime activities are related to insomnia in the general population: consequences for older people. J Am Geriatr Soc. 2001;49(4): 360-366.

10. Reid KJ, Martinovich Z, Finkel S, et al. Sleep: a marker of physical and mental health in the elderly. Am J Geriatr Psychiatry. 2006;14(10): 860-866.
11. Cho HJ, Lavretsky H, Olmstead R, Levin MJ, Oxman MN, Irwin MR. Sleep disturbance and depression recurrence in community-dwelling older adults: a prospective study. Am J Psychiatry. 2008;165(12): 1543-1550.

12. Montgomery P, Dennis J. Cognitive behavioural interventions for sleep problems in adults aged 60+. Cochrane Database Syst Rev. 2003;(1): CD003161.

13. Jacobs JM, Cohen A, Hammerman-Rozenberg R, Stessman J. Global sleep satisfaction of older people: the Jerusalem Cohort Study. J Am Geriatr Soc. 2006;54(2):325-329.

14. Jaussent I, Bouyer J, Ancelin ML, et al. Insomnia and daytime sleepiness are risk factors for depressive symptoms in the elderly. Sleep. 2011;34(8):1103-1110.

15. Sukegawa $\mathrm{T}$, Itoga $\mathrm{M}$, Seno $\mathrm{H}$, et al. Sleep disturbances and depression in the elderly in Japan. Psychiatry Clin Neurosci. 2003;57(3): $265-270$.

16. Perlis ML, Smith LJ, Lyness JM, et al. Insomnia as a risk factor for onset of depression in the elderly. Behav Sleep Med. 2006;4(2):104-113.

17. Roberts RE, Shema SJ, Kaplan GA, Strawbridge WJ. Sleep complaints and depression in an aging cohort: A prospective perspective. Am J Psychiatry. 2000;157(1):81-88.

18. Yokoyama E, Kaneita Y, Saito Y, et al. Association between depression and insomnia subtypes: a longitudinal study on the elderly in Japan. Sleep. 2010;33:1693-1702.

19. Mallon L, Broman JE, Hetta J. Sleeping difficulties in relation to depression and anxiety in elderly adults. Nord J Psychiatry. 2000;54(5): 355-360.

20. Koffel E, Watson D. The two-factor structure of sleep complaints and its relation to depression and anxiety. J Abnorm Psychol. 2009;118(1): 183-194.

21. van den Berg JF, Luijendijk HJ, Tulen JH, Hofman A, Neven AK, Tiemeier H. Sleep in depression and anxiety disorders: a populationbased study of elderly persons. J Clin Psychiatry. 2009;70(8): 1105-1113.

22. Spira AP, Stone K, Beaudreau SA, Ancoli-Israel S, Yaffe K. Anxiety symptoms and objectively measured sleep quality in older women. Am J Geriatr Psychiatry. 2009;17(2):136-143.

23. Germain A, Moul DE, Franzen PL, et al. Effects of a brief behavioral treatment for late-life insomnia: preliminary findings. J Clin Sleep Med. 2006;2(4):403-406.

24. Galea M. Subjective Sleep Quality in the Elderly: Relationship to Anxiety, Depressed Mood, Sleep Beliefs, Quality of Life, and Hypnotic Use [doctoral dissertation]. Victoria: Victoria University; 2008.

25. Kairouz SR, Boyer L, Nadeau M, Perreault M, Fiset-Laniel J. Troubles mentaux, toxicomanie et autres problèmes liés à la santé mentale chez les adultes québécois. Enquête sur la santé dans les collectivités canadiennes (cycle 1.2) [Mental disorders, substance abuse and other problems related to mental health in Quebec adults. Health Survey Canadian Community][dissertation]. Québec: Institut de la statistique du Québec; 2008. Available from: http://www.stat.gouv.qc.ca/statistiques/ sante/etat-sante/mentale/troubles-mentaux-toxicomanie.pdf. French. Accessed January 9, 2015.

26. Narrow WE, Rae DS, Robins LN, Regier DA. Revised prevalence estimates of mental disorders in the United States: using a clinical significance criterion to reconcile 2 surveys' estimates. Arch Gen Psychiatry. 2002;59(2):115-123.

27. Jackson ML, Sztendur EM, Diamond NT, Byles JE, Bruck D. Sleep difficulties and the development of depression and anxiety: a longitudinal study of young Australien women. Arch Womens Ment Health. 2014; 17(3):189-198.

28. Lopresti AL, Hood SD, Drummond PD. A review of lifestyle factors that contribute to important pathways associated with major depression: diet, sleep and exercise. J Affect Disord. 2013;148(1): $12-27$.

29. Zigmond AS, Snaith RP. The hospital anxiety and depression scale. Acta Psychiatr Scand. 1983;67(6):361-370. 
30. Préville M, Boyer R, Grenier S, et al. The epidemiology of psychiatric disorders in Quebec's older adult population. Can J Psychiatry. 2008;53:822-832.

31. Robins LN, Heizer JE, Croughan J, Rathcliff KS. National Institute of Mental Health Diagnostic Interview Schedule. Its history, characteristics, and validity. Arch Gen Psychiatry. 1981;38(4):381-389.

32. Adam AM, Potvin O, Callahan BL, Bastien C, Lorrain D, Desjardins S, Forget H, Préville M, Hudon C. Subjective sleep quality in non-demented older adults with and without cognitive impairment. Int J Geriatr Psychiatry. 2014;29(9):970-977.

33. Préville M, Boyer R, Vasiliadis HM, et al. One-year incidence of psychiatric disorders in Quebec's older adult population. Can J Psychiatry. 2010;55(7):449-457.

34. Buysse DJ, Reynolds CF 3rd, Monk TH, Berman SR, Kupfer DJ. The Pittsburgh Sleep Quality Index: a new instrument for psychiatric practice and research. Psychiatry Res. 1989;28(2):193-213.

35. Folstein MF, Folstein SE, McHugh PR. "Mini-mental state": A practical method for grading the cognitive state of patients for the clinician. J Psychiatric Res. 1975;12(3):189-198.

36. McCurry SM, Logsdon RG, Teri L, Vitiello MV. Evidence-based psychological treatments for insomnia in older adults. Psychol Aging. 2007;22(1):18-27.

37. Ohayon M, Caulet M, Lemoine P. [The elderly, sleep habits and use of psychotropic drugs by the French population]. Encephale. 1996;22(5):337-350. French.

38. American Psychiatric Association. DSM-IV-TR, Manuel diagnostique des troubles mentaux. [Diagnostic and Statistical Manual of Mental Disorder]. 4th ed. Paris: Masson; 2000. French.

39. Bloom HG, Ahmed I, Alessi CA, et al. Evidence-based recommendations for the assessment and management of sleep disorders in older persons. J Am Geriatr Soc. 2009;57(5):761-789.

40. López-Torres Hidalgo J, Navarro Bravo B, Párraga Martínez I, Andrés Pretel F, Téllez Lapeira J, Boix Gras C. Understanding insomnia in older adults. Int J Geriatr Psychiatry. 2012;27(10):1086-1093.

41. Fiorentino L, Martin JL. Awake at 4 Am: treatment of insomnia with early morning awakenings among older adults. J Clin Psychol. 2010;66(11):1161-1174.

42. Gruau S, Pottier A, Davenne D, Denise P. [Sleepiness-related road traffic accidents among elderly drivers: an analysis of the contributory factors: The preventive role of physical activity]. Recherche-Transports - Sécurité. 2003;79-80:134-144. French.

43. Aldao A, Mennin DS, Linardatos E, Fresco DM. Differential patterns of physical symptoms and subjective processes in generalized anxiety disorder and unipolar depression. J Anxiety Disord. 2010;24(2): 250-259.

44. Barlow DH, Durand VM. Psychopathologie: une perspective multi dimensionnelle. [Abnormal Psychology: An Integrative Approach]. 2nd ed. Paris: De Boeck Université; 2004. French.

45. Hofmann SG, Schulz SM, Heering S, Muench F, Bufka LF Psychophysiological correlates of generalized anxiety disorder with or without comorbid depression. Int J Psychophysiol. 2010;78(1):35-41.

46. CarlssonA.A half-century of neurotransmitter research: impact on neurology and psychiatry (Nobel lecture). Chembiochem. 2001;2(7-8): 484-493.

47. Haab F. Traitement de la nycturie. [Treatment of nycturia]. Correspondances en pelvi-perinéologie. 2004;4(2):23-25. French.

48. Rieder A, Kunze U, Groman E, Kiefer I, Schoberberger R. Nocturnal sleep-disturbing nicotine craving: a newly described symptom of extreme nicotine dependence. Acta Med Austriaca. 2001;28(1):21-22.

Psychology Research and Behavior Management

\section{Publish your work in this journal}

Psychology Research and Behavior Management is an international, peerreviewed, open access journal focusing on the science of psychology and its application in behavior management to develop improved outcomes in the clinical, educational, sports and business arenas. Specific topics covered include: Neuroscience, memory \& decision making; Behavior
49. Underner M, Paquereau J, Meurice JC. [Cigarette smoking and sleep disturbance]. Rev Mal Respir. 2006;23(3 Suppl):67-77. French.

50. Kunz R. [Palliative care for the elderly]. Swiss medical forum = Schweizerisches Medizin-Forum. 2002;5:100-108. French.

51. Gislason T, Reynisdóttir H, Kristbjarnarson H, Benediktsdóttir B. Sleep habits and sleep disturbances among the elderly - an epidemiological survey. J Intern Med. 1993;234(1):31-39.

52. Curless R, French JM, James OF, Wynne HA. Is caffeine a factor in subjective insomnia of elderly people. Age Ageing. 1993;22(1):41-45.

53. Drapeau C, Hamel-Hébert I, Robillard R, Selmaoui B, Filipini D, Carrier J. Challenging sleep in aging: the effects of $200 \mathrm{mg}$ of caffeine during the evening in young and middle-aged moderate caffeine consumers. J Sleep Res. 2006;15(2):133-141.

54. Landolt HP, Roth C, Dijk DJ, Borbély AA. Late-afternoon ethanol intake affects nocturnal sleep and the sleep EEG in middle-aged men. J Clin Psychopharmacol. 1996;16(6):428-436.

55. Lalonde P, Aubut J, Grunberg F, et al. Psychiatrie clinique, Une approche bio-psycho-sociale (Tome I). [Clinical Psychiatry: A bio-psycho-social approach] 3rd ed. Québec: Gaétan Morin; 1999. French.

56. Chasens ER, Sereika SM, Weaver TE, Umlauf MG. Daytime sleepiness, exercise, and physical function in older adults. J Sleep Res. 2007;16(1): 60-65.

57. Singh NA, Clements KM, Fiatarone MA. A randomized controlled trial of the effect of exercise on sleep. Sleep. 1997;20(2):95-101.

58. Pelletier-Fleury N, Rakotonanahary D, Fleury B. The age and other factors in the evaluation of compliance with nasal continuous positive airway pressure for obstructive sleep apnea syndrome: A Cox's proportional hazard analysis. Sleep Med. 2001;2(3):225-232.

59. douglas.qc.ca [homepage on the Internet]. Douglas Montreal: Mental Health University Institute; 2015. Available from: http://www.douglas. qc.ca. Accessed January 9, 2015.

60. dsm5.org [homepage on the Internet]. Arlington: American Psychiatric Association; 2014. Available from: http://www.dsm5.org. Accessed January 9, 2015.

61. Kvaal K, McDougall FA, Brayne C, Matthews FE, Dewey ME; MRC CFAS. Co-occurrence of anxiety and depressive disorders in a community sample of older people: results from the MRC CFAS (Medical Research Council Cognitive Function and Ageing Study). Int J Geriatr Psychiatry. 2008;23(3):229-237.

62. Beekman AT1, de Beurs E, van Balkom AJ, Deeg DJ, van Dyck R, van Tilburg W. Anxiety and depression in later life: Co-occurrence and communality of risk factors. Am J Psychiatry. 2000;157(1):89-95.

63. Yohannes AM, Baldwin RC, Connolly MJ. Prevalence of depression and anxiety symptoms in elderly patients admitted in post-acute intermediate care. Int J Geriatr Psychiatry. 2008;23(11):1141-1147.

64. Lapierre S, Boyer R, Desjardins S, et al. Daily hassles, physical illness, and sleep problems in older adults with wishes to die. Int Psychogeriatr. 2012;24(2):243-252.

65. De Matos MG, Calmeiro L, Da Fonseca D. [Effect of physical activity on anxiety and depression]. Presse Med. 2009;38(5):734-739. French.

66. King AC, Oman RF, Brassington GS, Bliwise DL, Haskell WL. Moderate-intensity exercise and self-rated quality of sleep in older adults: A randomized controlled trial. JAMA. 1997;277(1):32-37.

67. Floyd JA, Medler SM, Ager JW, Janisse JJ. Age-related changes in initiation and maintenance of sleep: a meta-analysis. Res Nurs Health. 2000;23(2):106-117.

modification \& management; Clinical applications; Business \& sports performance management; Social and developmental studies; Animal studies. The manuscript management system is completely online and includes a quick and fair peer-review system. Visit http://www.dovepress. com/testimonials.php to read real quotes from published authors. 